\title{
Reconsidering the Gospel According to Group Studies: A Neuropsychological Case Study Approach to Schizophrenia
}

\author{
Keith R. Laws \\ University of Cambridge, $U K$ \\ Peter J. McKenna \\ Addenbrooke's NHS Trust, Cambridge, UK \\ Rosaleen A. McCarthy \\ University of Cambridge, $U K$
}

\begin{abstract}
Individual patterns of performance on tests of: visual perception, language, executive function, memory, and face-processing, were examined in 10 schizophrenic patients who were preselected for having current WAIS IQ and premorbid NART IQ scores in the normal range. A lthough the patients showed some heterogeneity in the type, pervasiveness, and degree of cognitive impairment, a majority had severely impaired verbal recall and familiar face-naming. This contrasted with the low incidence and severity of impairment on tests of executive function, visual recall, recognition memory, naming, and unfamiliar faceprocessing. Contrasts between individual patients indicated that verbal recall and executive performance are independent in some patients and that memory appears to be the core deficit. The profile of impaired and preserved cognitive function revealed some important dissimilarities from the pattern that has emerged from group studies. Finally, face-naming correlated highly with the learning of unrelated pairedassociates, confirming a similarity with neurological patients who have person name anomia. It is suggested that both deficits might reflect a problem with learning "meaninglessness"' associations; th is interpretation is discussed with reference to a deficit at the level of the Supervisory Attentional System (Shallice, 1988).
\end{abstract}

Requests for reprints should be sent to Keith Laws who is now at the Department of Psychology, University of Hertfordshire, Hatfield Campus, College Lane, Hatfield, Herts AL10 9AB, UK.

Versions of this paper were presented at meetings of the Memory Disorders Research Society (Cambridge, August 1995) and the Regional British Association of Psychopharmacology Workshop (M anchester, November 1995). We would like to thank Jon Evans for the use of his famous faces and famous buildings tests and the use of his control norms. Thanks also to Tejinder Kondel, Jon Evans, and Nick Morton for helpful comments on this paper. KRL was supported by an M R Studentship.

(C) 1996 Psychology Press, an imprint of Erlbaum (UK) Taylor \& Francis Ltd 


\section{INTRODUCTION}

That the majority of schizophrenics are impaired on tests of cognitive functioning is no longer in doubt; however, the character, extent, and interpretation of their cognitive deficits remain uncertain. A common assertion is that, as a group, schizophrenic patients perform less well than normal controls on almost any cognitive task (e.g. Chapman \& Chapman, 1973). Indeed, they often show low IQ (Payne, 1973), IQ decline (Frith et al., 1991; Nelson et al., 1990), wide-ranging poor performance on neuropsychological test batteries (Kolb \& Whishaw, 1983; Taylor \& Abrams, 1984), and in a minority of chronically hospitalised patients, marked global intellectual dysfunction that is almost indistinguishable from dementia (Liddle \& Crow, 1984; Owens \& Johnstone, 1980; Stevens, Crow, Bowman, \& Coles, 1978). Against this, however, a number of recent studies have reported the presence of more specific cognitive deficits of executive function, memory, and some aspects of unfamiliar face-processing (for a review see McKenna, 1994).

Nonetheless, both clinicians and researchers acknowledge that schizophrenia presents in diverse forms and that heterogeneity is almost characteristic of this disorder. Such heterogeneity is most obvious in the diversity of symptoms expressed between and even, within patients across time; furthermore, as just outlined, the cognitive deficits associated with schizophrenia are also heterogeneous (e.g. Gruzelier et al., 1988; Liddle, 1987; Taylor \& Abrams, 1984). Such problems are not unique to schizophrenia research, but have also been addressed in the study of neurological disorders such as Alzheimer's disease (see Martin, 1988, 1990). Partial attempts to deal with schizophrenic heterogeneity have principally resulted in analyses of patients at more specific (clinical) levels: subtypes (e.g. Crow, 1980), syndromes (e.g. Liddle, 1987), and most recently, individual symptoms (see Frith, 1992), but not at the level of individual patients.

Nevertheless, as with the heterogeneity in Alzheimer's disease (Martin, 1990), the heterogeneity of schizophrenia raises doubts about the strategy of relying exclusively on group studies. Group study approaches to documenting cognitive function in schizophrenic patients present a "Catch-22', Almost all studies comment on this heterogeneity, but they fail to acknowledge that such analyses depend upon the examination of "known" homogeneous groups (see Shallice, 1988; Marshall \& Newcombe, 1984). For example, Strauss and Summerfelt (1994, p. 18) argue that: "Group comparison studies, using summarising statistics, the 'normal science' in schizophrenia research, may at times be misleading if not inappropriate.' Similarly, Bentall (1990, p. 293) suggests that the strategy of comparing schizophrenic and control groups, amounts to "... the comparison of one group of people who in all probability have nothing in common with another group of people who also probably have nothing in common.' Despite this, a more theoretically determined way of dealing with heterogeneity may be achievable within cognitive neuropsychol- 
ogy. Single case studies (alongside group studies) may provide a method that can both accommodate and exploit the heterogeneous character of schizophrenia that has, for so long, dogged research into this disorder (for recent applications see: David, 1994a,b; Laws \& McKenna, in press; Laws, McKenna, \& McCarthy, 1995; McKay, McKenna, \& Laws, in press; Shallice, Burgess, \& Frith, 1991; Tamlyn et al., 1991).

Although group studies commonly report that patients fail many tests, little can be inferred by documenting associations of deficits (see Shallice, 1988). To consider a neuropsychological deficit as selective or specific, performance should be impaired on a series of tasks sensitive to the relevant function, and intact on tasks tapping unrelated functions (i.e. a single dissociation). It is also necessary to show that any putative specific deficit is not an aspect of a more general intellectual decline. Dissociations of test performance might be best examined in patients with preserved intellectual function and few neuropsychological deficits. As David (1994a) has recently remarked, the single case method might also aid theory development in schizophrenia research (p. 1): “A single 'ideal' case with one of these 'pure' deficits can thus become the lynch-pin of theoretical development. Better still is the identification of a pair of cases where one has lost function $\mathrm{X}$ but has a normal function $\mathrm{Y}$ and the other has the opposite pattern of abilities/disabilities, the magic double dissociation.',

The most common claim has been that schizophrenia is characterised by a specific deficit of "frontal lobe", or "executive", functioning (see Shallice et al., 1991). A plethora of group studies have examined executive function in schizophrenic patients (Blanchard \& Neale, 1994; Braff et a1., 1991; Crawford, Obonswain, \& Bremner, 1993; Elliott, McKenna, Robbins, \& Sahakian, 1995; Goldberg et al., 1987, 1988; Gruzelier, Seymour, Wilson, Jolley, \& Hirsch, 1988; Liddle \& Morris, 1991; Morice, 1990; Morrison-Stewart et a1., 1992; Saykin et al., 1991). Most group investigations reporting executive impairments have, however, failed to specify the status of executive function. Given the variability of executive tests and the need for converging and diverging operations, too many studies have: (1) relied on single executive tests (typically the WCST); (2) have failed to also examine performance on nonexecutive tests; or (3) have failed to control for the current state of patient intellectual functioning. Moreover, where some attempt has been made to control for these factors, the results do not reveal a specific executive dysfunction in schizophrenia (e.g. Braff et a1., 1991; Elliott et al, 1995).

A recent single case study analysis by Shallice et al. (1991) explicitly addressed the "specificity" issue by examining both executive and nonexecutive functions in five chronically hospitalised schizophrenic patients (with a wide range of current intellectual status). They found that all five showed poor performance on a number of executive tests. In two cases, poor executive function occurred in relative isolation, being accompanied by relatively preserved IQ and inconsistent but substantial deficits on memory tests. In the remaining patients, executive dysfunction was accompanied by poor perfor- 
mance on other tests and IQ decline. Their analysis of these patients led Shallice et al. to conclude that executive impairment was a common denominator in schizophrenic neuropsychological impairment-one that occurred against a background of variable and generalised deficits.

In contrast to the attention directed toward executive dysfunction, memory impairment has not been traditionally viewed as a cardinal feature of schizophrenia. Yet, two recent studies have reported a memory deficit in schizophrenic patients that was disproportionate to general intellectual impairment (McKenna et al., 1990) and performance on tests of executive, language, and perceptual functioning (Saykin et al., 1991). One study using the single case study approach (Tamlyn et al., 1992) also supports the view that some schizophrenics show a relatively isolated memory impairment. Indeed, a profile of intact short-term memory in the presence of impaired long-term memory performance has been reported in several studies (e.g. Duffy \& O'Carroll, 1994; Goldberg et al., 1993b; McKenna et a1., 1990; Tamlyn et al., 1992).

Another purported area of specific deficit in schizophrenia is face-processing (for reviews see Cutting, 1985; Morrison, Bellack, \& Mueser, 1988; see also Archer, Hay, \& Young, 1992, 1994; Gaebel \& Wolwer, 1992; Kerr \& Neale, 1993; Kline, Smith, \& Ellis, 1992). It has been proposed that the recognition of faces and facial expression are more impaired than any other visual cognitive function in schizophrenia (Grüsser \& Landis, 1988) and furthermore, that disturbed identification of facial emotion may be the crucial factor underlying the interpersonal difficulties of schizophrenics (Feinberg, Rifkin, Schaffer, \& Walker, 1986). Some argue that schizophrenics may have a differential or specific deficit in the processing of facial emotion (e.g. Borod, Martin, \& Alpert, 1993; Heimberg, Gur, Erwin, \& Shtase1, 1992; Walker, McGuire, \& Bettes, 1984), whereas others have found a more generalised deficit also affecting the matching of unfamiliar faces for identity (e.g. Archer et a1., 1992; Kerr \& Neale, 1993 ) and discriminating age from faces (Gessler et a1., 1989; Heimberg et al., 1992). The specificity of any face-processing deficit must also be considered in the context that none of these studies have examined other forms of complex visual-processing and so, cannot rule out a general perceptual deficit or even, impaired vision (see review by Morrison et al., 1988). Finally, apart from two studies examining familiar face-occupation matching (Archer et al., 1992, 1994), none have examined the naming and identification of familiar faces in schizophrenic patients. This is especially surprising as disorders of familiar face recognition (e.g. Capgras' syndrome) are most frequently reported in patients with a schizophrenic diagnosis (for reviews see Berson, 1983; Kimura, 1986).

So, many claims for specific deficits in schizophrenia appear to be confounded by problems primarily relating to patient heterogeneity and the failure of group studies to demonstrate the specificity of deficits. Using a case study approach and a similar methodology to that employed by Shallice et al. (1991), the present investigation details the incidence, severity, and pattern of 
neuropsychological deficits found in 10 schizophrenic patients. These patients, who have relatively "well-preserved" intellect and clinical status, potentially offer an opportunity to examine schizophrenia in a less cluttered state. The study focuses on the cognitive functions that are commonly investigated in the literature, but also through the performance of individual patients across multiple tests in each domain of cognitive function.

\section{CASE DESCRIPTIONS}

A total of 10 patients ( 8 male and 2 female) were drawn from a population of chronic schizophrenic patients under the care of one of the authors (PJM). The patients were selected because:

(1) current full-scale IQs (Wechsler Adult Intelligence Scale, WAIS: Wechsler, 1955) were in the average or above average range;

(2) estimated premorbid IQ (National Adult Reading Test, NART: Nelson \& O'Connell, 1978) were in the normal range; and

(3) they scored above the cut-off point for dementia on the Mini-Mental State Examination (MMSE: Folstein, Folstein, \& McHugh, 1975).

All 10 patients met Research Diagnostic Criteria for schizophrenia (RDC: Spitzer, Endicott, \& Robbins, 1978) and none had any history of organic brain disease, head injury, or alcohol or drug abuse. English was the first language in nine of the patients; one (FS), although fluent in English, spoke German until the age of seven when he emigrated to Britain. Although all patients had long histories of illness, they showed little clinical deterioration (clinical details are summarised in Table 1). W ith the exception of one patient (TG), who had been living in a resettlement unit for 18 months whilst awaiting a hostel placement, the patients were living in the community. One patient (TG) was receiving anticholinergic medication, one was unmedicated $(\mathrm{JH})$, and the remainder were receiving various dosages of the atypical neuroleptic clozapine.

\section{DATA ANALYSIS}

A comprehensive battery of standard neuropsychological tests was administered to assess a wide range of intellectual, visual perceptual, language, mnestic, executive, and face-processing functions. Following the approach of Shallice et a1. (1991), patient performance was converted into impairment indices using published age-matched normative data as follows: $0=>25$ th percentile; $1=10-24$ th percentile; $2=5-9$ th percentile; and $3=5$ th percentile. Where published norms were not available, control data were collected (see text for specific details). Interpretation of results within the text concentrates on performances below the 5 th percentile-a score of " 3 ", - this was done to reduce the risk of falsely inferring impairment, to emphasise the most severe cases and to simplify data presentation. 
TABLE 1

Clinical Features of the Patients

\begin{tabular}{|c|c|c|c|c|c|}
\hline Patient & Age & Sex & Main Features of History & $\begin{array}{l}\text { Current } \\
\text { Positive } \\
\text { Symptoms }\end{array}$ & $\begin{array}{l}\text { Current } \\
\text { Negative } \\
\text { Symptoms }\end{array}$ \\
\hline $\mathrm{CH}$ & 40 & $\mathrm{~F}$ & $\begin{array}{l}\text { Delusions, auditory hallucinations, and } \\
\text { formal thought disorder. Continues to } \\
\text { show all symptoms. }\end{array}$ & Moderate & Moderate \\
\hline $\mathrm{CN}$ & 45 & M & $\begin{array}{l}\text { Delusions and continuous auditory } \\
\text { hallucinations. Marked improvement on } \\
\text { clozapine last } 2 \text { years. }\end{array}$ & $M$ ild & $\mathrm{M}$ inimal \\
\hline D B & 34 & M & $\begin{array}{l}\text { Initial episode of florid psychosis. } \\
\text { Subsequently single hypochondriacal } \\
\text { delusion and moderate negative } \\
\text { symptoms }\end{array}$ & M ild & Moderate \\
\hline FS & 58 & M & $\begin{array}{l}\text { Several episodes of delusions and } \\
\text { olfactory hallucinations. For several years } \\
\text { has shown only delusions of reference. }\end{array}$ & $M$ ild & $\mathrm{M}$ inimal \\
\hline $\mathrm{JH}$ & 56 & M & $\begin{array}{l}\text { Florid, unremitting delusions, and } \\
\text { hallucinations in all modalities. }\end{array}$ & M arked & M inimal \\
\hline LR & 29 & $\mathrm{~F}$ & $\begin{array}{l}\text { Episodes of florid psychosis with good } \\
\text { recovery from age } 16 \text {. Excellent response } \\
\text { to clozapine } 2 \text { years ago. }\end{array}$ & None & None \\
\hline R A & 34 & M & $\begin{array}{l}\text { Long prodrome of nonspecific symptoms } \\
\text { giving way to florid delusions and } \\
\text { hallucinations. Currently shows only } \\
\text { auditory hallucinations. }\end{array}$ & Moderate & M ild \\
\hline SD & 32 & M & $\begin{array}{l}\text { Episodes of delusions, hallucinations, and } \\
\text { first-rank symptoms. Now left with } \\
\text { partially held grandiose and other } \\
\text { delusions. }\end{array}$ & $\begin{array}{l}\text { M ild- } \\
\text { M oderate }\end{array}$ & M ild \\
\hline TG & 40 & M & $\begin{array}{l}\text { Delusions, hallucinations, and first-rank } \\
\text { symptoms. Improvement followed by } \\
\text { development of multiple grandiose } \\
\text { delusions. }\end{array}$ & M arked & M ild \\
\hline $\mathrm{TM}$ & 29 & M & $\begin{array}{l}\text { Two initial episodes of delusions and } \\
\text { hallucinations. Residual auditory } \\
\text { hallucinations and occasional episodes of } \\
\text { formal thought disorder and bizarre } \\
\text { behaviour. }\end{array}$ & M ild & M ild \\
\hline
\end{tabular}

As originally noted by Chapman and Chapman (1973), it is difficult to demonstrate specific deficits in schizophrenia research, because patients often have a generalised deficit that interacts with task difficulty; leading to relatively worse performances on more difficult tasks. As advised by Chapman and Chapman, we avoided making direct statistical comparisons between patient and control groups, but compared each patient's performance on any one test with his/her own performance on other relevant tests. The conversion of test scores 
into scaled scores, derived from age-matched control norms, meant that such comparisons were also made on a normatively defined common scale.

\section{STANDARD NEUROPSYCHOLOGICAL TESTS}

\section{Intellectual Functioning}

The results from tests of general intellectual functioning are shown in Table 2 . The NART yielded estimates of premorbid IQ within the normal range for all patients (range 100-124). All patients in this study had current full-scale W AIS IQs (range 91-122) that were above the 25th percentile (in the average, high average, or superior range). Despite this, four patients showed a significant WAIS-NART discrepancy (i.e. an IQ drop of $13+$ points; being below the 5 th percentile in normal controls: see Nelson, 1982). This primarily reflected a lowering of PIQ; five patients showed a PIQ-VIQ discrepancy-lower PIQ than VIQ - of a magnitude that occurs below the 5th percentile in normal controls; this is comparable in type and magnitude to that often reported in other studies (for a review see Alyward, Walker, \& Betts, 1984). Finally, the W AIS-NART discrepancy did not significantly correlate with any of the cognitive measures used in this study.

\section{Visual Perception}

Five subtests from the Visual Object and Space Perception battery (VOSP: Warrington \& James, 1991, Incomplete Letters, Shape Detection, Position Discrimination, Object Decision, and Silhouettes), and the unusual views task (Warrington \& Taylor, 1973) revealed scattered impairment (see Table 3). No test revealed more than a minority of impaired performances and only three patients scored below the 5 th percentile across all tests.

TABLE 2

Tests of Intellectual Function

\begin{tabular}{lrrrrrrrrrrr}
\hline & \multicolumn{10}{c}{ Patient } \\
\cline { 2 - 9 } Test & CH & CN & D B & FS & JH & LR & R A & SD & TG & TM & Mean \\
\hline Full-scale IQ & 98 & 94 & 110 & 122 & 95 & 94 & 91 & 98 & 96 & 97 & 99.5 \\
W A IS (VIQ) & 103 & 102 & 118 & 123 & 93 & 96 & 91 & 111 & 95 & 105 & 103.7 \\
W A IS (PIQ) & 92 & 85 & 94 & 118 & 99 & 91 & 94 & 89 & 99 & 88 & 94.9 \\
NART & 115 & 105 & 109 & 113 & 106 & 108 & 100 & 124 & 107 & 116 & 110.3 \\
NART-W A IS & -17 & -11 & 1 & 9 & -11 & -14 & -9 & -26 & -11 & -19 & -10.8 \\
M M SE & 29 & 25 & 27 & 28 & 28 & 25 & 25 & 28 & 28 & 27 & 27.2 \\
\hline
\end{tabular}




\section{Language}

The results of language tests are shown in Table 3. Patient scores on the Graded Naming Test (McKenna \& Warrington, 1983) were all in the range predicted by their WAIS vocabulary and NART scores. All patients, except JH and LR, performed normally on the Pyramids and Palm Trees test (Howard \& Patterson, 1992). Only one patient (JH) showed any impairment on the Token test of receptive syntactical function (De Renzi \& Faglioni, 1978).

\section{Executive Function}

The three tests of executive function: the Modified Card Sort Test (MCST: Nelson, 1976); the Cognitive Estimates Test (Shallice \& Evans, 1978) and category fluency (averaged across four categories: animals, birds, vegetables, fruits), also revealed scattered impairment. No patient was impaired on all three; three patients (TG, SD, and LR) were impaired on two tests; four patients (DB, FS, JH, and $\mathrm{CN}$ ) were impaired on one test; and three (TM, RA, and $\mathrm{CH}$ ) were not impaired on any executive task. Most patients performed normally on the MCST and made very few perseverative errors.

\section{Episodic Memory}

Immediate Memory. Results from all memory tests are shown in Table 3. All patients were intact on forward auditory digit span, and one patient (CN) had a mild impairment of backward auditory digit span (Wechsler Memory ScaleRevised: Wechsler, 1987). A higher incidence of impairment was found on the Corsi blocks task, although this tended to be quite mild for both forward and backward spans.

\section{Long-term Memory}

Recognition. On the Warrington Recognition Memory tests (Warrington, 1984), no patient achieved a higher face-than word-scaled score. All patients had normal word recognition (indeed, all scored above the 75 th percentile for their age group and five scored above the 95 th percentile). However, three (TG, RA, LR) had impaired face recognition and two of these (TG and LR) were also impaired on the Topographic Recognition Memory test (Warrington, personal communication), a demanding three-choice recognition test using photographs of street scenes in Camden Town, London.

Recall. Recall memory was tested with the Logical memory (story recall), Paired-Associate (P-A) learning (hard and easy pairs), and Visual Reproduction subscales from the Wechsler Memory Scale-Revised (Wechsler, 1987). On the Visual Reproduction test, all patients achieved scores with in the normal range. In contrast, seven patients had impaired immediate recall on the Logical 
TABLE 3

Standard Neuropsychological Tests

\section{Patient}

Test

$\begin{array}{llllllllll}\mathrm{CH} & \mathrm{CN} & \mathrm{DB} & \mathrm{FS} & \mathrm{JH} & \mathrm{LR} & \mathrm{RA} & \mathrm{SD} & \mathrm{TG} & \mathrm{TM}\end{array}$

Visual perception

Shape Detection (1)

Incomplete Letters (1)

Position Discrim ination (1)

Object Decision (1)

Silhouettes (1)

Unusual Views Test (2)

$\begin{array}{llllllllll}0 & 0 & 0 & 0 & 0 & 0 & 0 & 0 & 0 & 0 \\ 0 & 1 & 0 & 0 & 0 & 0 & 2 & 0 & 0 & 0 \\ 1 & 0 & 0 & 0 & 0 & 0 & 0 & 0 & 0 & 0 \\ 3 & 0 & 2 & 0 & 2 & 0 & 0 & 0 & 3 & 0 \\ 3 & 0 & 0 & 0 & 2 & 3 & 2 & 0 & 3 & 0 \\ 0 & 0 & 0 & 0 & 1 & 1 & 0 & 0 & 3 & 0\end{array}$

\section{Language}

Graded Naming Test (3)

Pyramids and Palm Trees (4)

Modified Token Test (5)

$\begin{array}{ll}0 & 0 \\ 0 & 0 \\ 0 & 0\end{array}$

Executive Function

$\operatorname{MCST}(6)$

Cognitive Estimates (7)

Category Fluency (11)

$\begin{array}{llllllllll}0 & 3 & 0 & 0 & 0 & 0 & 0 & 0 & 3 & 0 \\ 0 & 0 & 0 & 0 & 0 & 2 & 0 & 2 & 0 & 0 \\ 0 & 0 & 2 & 2 & 1 & 1 & 0 & 2 & 2 & 0\end{array}$

Memory

Digit span (forward) (8)

Digit span (backward) (8)

B lock span (forward) (8)

B lock span (backward) (8)

RMT Faces (9)

RM T Words (9)

Topographic (10)

Paired Associates (8)

Logical memory (8)

Visual reproduction $(8)$

\begin{tabular}{llllllllll}
0 & 0 & 0 & 0 & 0 & 0 & 0 & 0 & 0 & 0 \\
0 & 1 & 0 & 0 & 0 & 0 & 0 & 0 & 0 & 0 \\
0 & 1 & 0 & 0 & 1 & 1 & 1 & 0 & 0 & 0 \\
0 & 2 & 0 & 2 & 0 & 2 & 1 & 0 & 0 & 0 \\
0 & 0 & 0 & 0 & 1 & 3 & 2 & 0 & 3 & 0 \\
0 & 0 & 0 & 0 & 0 & 0 & 0 & 0 & 0 & 0 \\
0 & 0 & 0 & 0 & 0 & 1 & 0 & 0 & 3 & 0 \\
3 & 3 & 3 & 1 & 1 & 3 & 3 & 0 & 3 & 0 \\
0 & 3 & 1 & 0 & 1 & 3 & 3 & 0 & 3 & 3 \\
0 & 0 & 0 & 0 & 0 & 0 & 0 & 0 & 0 & 0 \\
\hline
\end{tabular}

(1) Warrington \& James (1991); (2) Warrington \& Taylor (1973); (3) McKenna \& Warrington (1983); (4) Howard \& Patterson (1992); (5) De Renzi \& Faglioni (1976); (6) Nelson (1976); (7) O'Carroll, Egan, \& MacKenzie (1994); (8) W echsler (1987); (9) Warrington (1984); (10) W arrington (personal communication); (11) unpublished data from 10 age-matched controls.

Memory test ( $<5$ th percentile in five) and eight patients had impaired immediate recall on the $\mathrm{P}-\mathrm{A}$ learning task $(<5$ th percentile in six). Two patients ( $\mathrm{TG}$ and DB) failed to recall any unrelated word pairs, though the remainder of the patients performed better. In contrast, $8 / 10$ patients were impaired on the related pairs (although this may reflect that normal controls score at ceiling).

A qualitative analysis of patient responses showed that one-quarter (26/104) of all P-A errors consisted of "confabulatory" responses that were semantically 
related to the cue word and not part of the original word-pair lists (e.g. "Fruit $\rightarrow$ Nut", rather than "Fruit $\rightarrow$ Apple"'). The patients showed a tendency to produce significantly more confabulatory errors to semantically related (easy) than unrelated (hard) word pairs $\left[51 \%\right.$ vs. $\left.32 \%\left(\chi^{2}=3.569, P=.05\right)\right]$. This suggests that patients offer confabulatory responses when those responses have some plausibility; this would account for their greater willingness to confabulate to related word pairs and not to unrelated word pairs. Hence, they may be offering plausible suggestions, rather than implausible confabulations. The patients showed no evidence of confabulation on the logical memory task (cf. Nathaniel-James \& Frith, 1996).

\section{Summary}

This series of schizophrenic patients showed both a smaller mean IQ decline (i.e. NART-WAIS) and a higher current IQ than patients reported in recent large studies of chronic (Nelson et al., 1990) and acute patient groups (Frith et al., 1991), and chronically hospitalised and community-resident schizophrenic patients (Crawford et al., 1992). Indeed, differences of the magnitude reported here occur in $5-10 \%$ of the normal population (Nelson, 1982). Surprisingly, the two patients (TM and SD) who had the largest NART-W AIS discrepancy, also had the least impaired test performances of the group (one and none that were $<5$ th percentile). Removing these makes little difference (apart from reducing the group mean IQ decline to 7.8 points) to a prominent pattern of memory deficits and implies that absolute IQ decline does not contribute, in a crucial way, to this profile of cognitive impairment. That no significant correlations existed between IQ decline and performance on any other test, also accords with this conclusion.

Tests of language function revealed a low incidence and severity of impairment; however, a coherent, albeit modest pattern of impairment did emerge on tests of visual perception. As appears to be true of Shallice et al.'s (1991) cases, perceptual deficits appeared to be more frequent and severe when complex levels of object recognition were examined (i.e. on tests that required naming and/or identification). Despite this, the patients had intact object-naming on the gradednaming test. With this in mind, the object recognition disorder may reflect the greater "noise", of the perceptual tasks examined here and in the Shallice et al., study (i.e. Silhouettes, Object Decision, and Unusual Views). In the se three tasks, the stimuli are "degraded", in so far as they use noncanonical views of objects; whereas the graded-naming test uses canonical (i.e. nondegraded) stimuli. Such an account is compatible with current models of object recognition and suggests that a minority of schizophrenic patients may have an apperceptive agnosia as described by Warrington and Taylor (1973).

Executive test impairment was much lower than that reported in the Shallice et al. (1991) study. There was no evidence of either a uniform pattern of deficit or a task difficulty/sensitivity effect across tests or patients - at least in so far as 
no task produced more than two patient scores $<5$ th percentile and no patient failed all three tasks. Shallice (personal communication) suggests that a reasonable index of significant executive dysfunction might be two of three executive task performances $<5$ th percentile-using this criterion, none of the patients were significantly impaired. The divergence between our cases and those of Shallice et al. (1991) possibly reflects differences in the severity of pathology-by comparison with Shallice et al.'s chronically hospitalised patients, $9 / 10$ patients in the current study were community-dwelling. Therefore, severe and extensive executive impairment may be a function of increasing severity/chronicity of illness and is perhaps less ubiquitous in schizophrenics than first speculated.

The most striking result was the dissociation between impaired verbal recall and both normal verbal recognition memory and normal visual recall in all patients. Although most patients were receiving the atypical neuroleptic, clozapine, evidence suggests that long-term (verbal) memory is unaffected, or may even be improved by this drug (Goldberg et al., 1993a; Meltzer, 1992). The results from the span tasks are consistent with previous findings showing that this aspect of immediate memory remains intact in most patients. These findings suggest that some of the fundamental memory deficit in some schizophrenic patients, may be affecting long-term verbal recall. Finally, the dissociation between impaired verbal recall and intact executive function in three patients (TM, RA, and $\mathrm{CH}$ ), is consistent with a fractionation of these deficits in some schizophrenic patients; and the greater incidence of memory than executive dysfunction, suggests that memory impairment is the core cognitive deficit. This is further supported by the observation that the verbal recall was so specific-in three patients (DB, RA, and TM), this was their only impaired performance (i.e. $<5$ th percentile).

Against this, the performance of individual patients was heterogeneous, both in the number and in the type of impaired performance: For example, the proportion of test scores below the 5 th percentile ranged from none (SD and FS) to over $50 \%$ (TG). For the majority of patients, impaired verbal recall is superimposed on an assortment of preserved and impaired performances on other tests. Of course, normal individuals show some variability of performance within the normal range and some of the background heterogeneity reported here in schizophrenics may similarly reflect such normal variability. In contrast, the high incidence of verbal recall deficit is unlikely to reflect normal fluctuation.

\section{TESTS OF FACE-PROCESSING}

Various aspects of face-processing were analysed within the framework of faceprocessing proposed by Bruce and Young (1986, see fig. 1): These included tests tapping the processing of unfamiliar faces for affect and identity; and familiar faces for naming and identification. 


\section{Unfamiliar Face-processing}

All tasks were designed so that no "labelling", responses were required-this was to eliminate complex linguistic components in the tasks and to minimise differences in task requirements, simple forced-choice judgements were used (except for the Benton test). Within the Bruce and Young model, these tests appear to tap two main levels of face-processing: directed visual-processing and affect recognition.

\section{Method and Procedure}

1. Directed visual-processing was examined with the Benton face-matching task (Benton, Hamsher, Varney, \& Spreen, 1978) and two other tests (based on McNeil \& Warrington, 1991), that examined age ordering of faces and matching faces for identity across age:

(a) Benton face-matching task: This task requires the matching of a single target face with (up to) three identical faces from a choice of six, each presented at different angles or in different lighting conditions.

(b) Age-ordering of unfamiliar faces: Subjects were presented with 24 sets of four different (same sex) faces and asked to order each quartet from youngest to oldest.

(c) Matching for identity across age: 20 pairs of unfamiliar faces (either the same person at different ages or different people at different ages) were presented for a "same", or "different", identity judgement for each pair. It was assumed that this task broadly taps similar processes to those independently examined in tasks (a) and (b).

2. Affect-processing was examined with two forced-choice tests (taken from McNeil \& Warrington, 1991), tapping both positive and negative affect:

(a) Anger judgement: This required subjects to examine 20 pairs of unfamiliar faces and to point to the face expressing more anger in each pair.

(b) Happiness judgement: This required subjects to examine 20 pairs of unfamiliar faces and to point to the face expressing more happiness in each pair.

\section{Results}

The performance of patients was compared to a 14 age-matched normal controls (see Table 4). On no single task, did more than three patients score below the 5 th percentile and two patients (SD and LR) showed no evidence of impairment. 
TABLE 4

Tests of Unfamiliar Face-processing

Patient

\begin{tabular}{|c|c|c|c|c|c|c|c|c|c|c|}
\hline \multirow[b]{2}{*}{ Test } & \\
\hline & $\mathrm{CH}$ & $\mathrm{CN}$ & D B & FS & $\mathrm{JH}$ & LR & R A & SD & TG & $\mathrm{TM}$ \\
\hline Benton Faces ${ }^{a}$ & 0 & 0 & 0 & 3 & 0 & 0 & 1 & 0 & 3 & 0 \\
\hline $\mathrm{Age}^{\mathrm{b}}$ & 0 & 3 & 3 & 0 & 0 & 0 & 0 & 0 & 3 & 0 \\
\hline Identity-age $\mathrm{e}^{\mathrm{b}}$ & 3 & 3 & 2 & 2 & 0 & 0 & 2 & 0 & 2 & 3 \\
\hline Anger ${ }^{b}$ & 3 & 0 & 0 & 0 & 3 & 0 & 0 & 0 & 1 & 3 \\
\hline Happiness ${ }^{b}$ & 0 & 0 & 0 & 0 & 0 & 0 & 0 & 0 & 0 & 0 \\
\hline
\end{tabular}

${ }^{\text {a }}$ Patient performance was compared with test norms.

${ }^{\mathrm{b}}$ Patient performance was compared to 14 age-matched normal controls ( $\mathrm{mean}=37.1 \pm 10.5$ : $t=.49, \mathrm{df}=22, P=.62)$.

Only one patient (JH) had a selective affect-processing deficit; the reverse profile, of selectively preserved affect-processing, occurred in $50 \%$ of the patients. All patients with impaired age-ordering or impaired identity-matching were also impaired at matching identity-across-age; conversely, however, two patients $(\mathrm{CH}$ and $\mathrm{TM})$ had unimpaired age-ordering and unimpaired identitymatching, but performed poorly at matching faces for identity across age.

\section{Summary}

There was no common or consistent profile among the patients on unfamiliar face-processing tests and in particular, little evidence of selectively impaired affect judgement. The finding of worse performance at judging negative than positive affect is consistent with previous reports and may reflect the greater discrim inatory power of faces expressing negative affect (see Novic, Luchins, \& Perline, 1984). Finally, the higher incidence of impaired judgement of identityacross-age compared to simple identity judgements and age-ordering, suggests that the former task may be tapping a task difficulty effect.

\section{FAMILIAR FACE-NAMING AND IDENTIFICATION}

\section{Method and Procedure}

A set of 53 mixed black and white and colour photographs taken from popular magazines; the pictures were selected to have high salience and included famous people from various occupations and decades (e.g. Marilyn Monroe, John Major, Nelson Mandela, Adolf Hitler, Elvis Presley). 


\section{Results}

The performance of patients was compared with 20 NART IQ and age-matched normal control subjects (see Table 5). Performance was analysed as follows: providing the name was scored as "named"; identification was divided into "general" and "specific": if the face was not named and the person's occupation (e.g. Robert Redford $\rightarrow$ "Actor") was given, then responses were scored as "identified-general"; and if more specific information was also provided (e.g. Robert Redford $\rightarrow$ " Actor, who starred in the film Butch Cassidy and the Sundance Kid"), then responses were scored as "identified-specific".

Seven of the ten patients scored below the 5 th percentile and named fewer faces than any of the age- and IQ-matched control subjects. Three of the patients (DB, LR, and TG) also had impaired retrieval of general identifying information. Almost all errors were omissions. Unlike normal subjects and older persons, the schizophrenic patients showed little tendency to make tip-ofthe-tongue responses. Although the majority of patients provided occupations for a normal number of faces, they appeared to experience a complete block for name phonology (or other information about the person's name). A comparison of the number of named faces that were famous pre- and postmorbid for each patient, revealed that two patients had better premorbid recall (CN and LR); two others showed the reverse (DB and FS); and the remaining patients showed no difference.

TABLE 5

Tests of Familiar Face and Building-naming and Identification

\begin{tabular}{|c|c|c|c|c|c|c|c|c|c|c|}
\hline \multirow[b]{2}{*}{ Test } & \multicolumn{10}{|c|}{ Patient } \\
\hline & $\mathrm{CH}$ & $\mathrm{CN}$ & D B & FS & $\mathrm{JH}$ & LR & R A & SD & TG & T M \\
\hline \multicolumn{11}{|l|}{ Familiar Faces ${ }^{\mathrm{a}}$} \\
\hline $\mathrm{Nam}$ ing & 3 & 3 & 3 & 3 & 0 & 3 & 3 & 0 & 3 & 0 \\
\hline Specific Identification & 2 & 2 & 3 & 1 & 0 & 3 & 1 & 0 & 3 & 0 \\
\hline General Identification & 0 & 0 & 3 & 1 & 0 & 3 & 0 & 0 & 3 & 0 \\
\hline \multicolumn{11}{|l|}{ Familiar Building $s^{\mathrm{b}}$} \\
\hline $\mathrm{Nam}$ ing & 0 & 0 & 3 & 0 & 3 & 1 & 0 & 0 & 0 & 0 \\
\hline Specific Identification & 0 & 0 & 3 & 0 & 3 & 1 & 0 & 0 & 0 & 0 \\
\hline General Identification & 0 & 0 & 3 & 0 & 3 & 1 & 0 & 0 & 0 & 1 \\
\hline
\end{tabular}

${ }^{a}$ Patient performance was compared to a group of 20 age-matched normal controls $($ mean $=40 \pm 16.6: t=.24, d f=28, P=.81)$ and NART IQ (mean $=107.95 \pm 8.9: t=1.16, d f=28$, $P=.25)$.

${ }^{b}$ Patient performance was compared to a group of 10 age-matched normal controls $($ mean $=43.1 \pm 16.6: t=.56, d f=18, P=.57)$ and NART IQ $($ mean $=109.1 \pm 10.5: t=1.14, d f=18$, $P=.26)$. 
Studies of neurological patients with person name anomia, report that such patients tend to be impaired at forming arbitrary links in verbal memory: In particular, with the unrelated word pairs in the Wechsler Paired-Associate Learning Test (see Hittmair-Delazer, Denes, Semenza, \& Mantova, 1994; Lucchelli \& De Renzi, 1992; Semenza \& Zettin, 1989). This relationship was also confirmed here in schizophrenic patients, as face-naming was very highly correlated with recall of unrelated word pairs $(r=.917, P=.0001)$, but not for the related pairs $(r=.47, P>.05)$ or any other cognitive variable.

\section{Summary}

Familiar face-naming was both severely and commonly impaired. W ithin Bruce and Young's model of face-processing (see Fig. 1), this deficit reflects dysfunction at the levels of the Face Recognition Units (FRUs), Person Identity Nodes (PINs), or name lexicon. The precise locus of the deficit would depend on whether the patients also had impaired face identification. Patients with more intact identification ( $\mathrm{CH}, \mathrm{CN}, \mathrm{FS}$, and RA) appear to have a deficit at the level of the name lexicon (or in the transmission of sufficient PIN information for names to be activated in the name lexicon). In contrast, impaired naming and identification (DB, LR, and TG) are more consistent with a deficit at an earlier stage of processing: Either at the FRUs or PINs (i.e. at the level of person knowledge or semantics). As predicted by the model, the impairments showed a distinctive hierarchical pattern - impaired general information (occupation) was invariably accompanied by impaired specific information (names and biographical details) and the reverse never occurred.

The failure to find differentially impaired postmorbid face-naming, makes an acquisition or consolidation deficit unlikely. Given that all patients performed well on the adult graded-naming test (see language section earlier), this deficit does not form part of a general anomia. Nevertheless, the face-naming deficit shows the same relationship with P-A learning that has been documented in neurological patients with selectively impaired person name retrieval (or person name anomia). Person (or proper) names may be more difficult to recall than common nouns because proper names are "meaningless", or arbitrary (Cohen, 1990; Cohen \& Burke, 1993). Hence, the patients have a problem with the retrieval of "meaningless", or arbitrary associations. However, compared to common nouns, person names are also unique and therefore the deficit might reflect this feature. The final test examined whether the patients also have difficulty with another category of unique names-those of familiar buildings and monuments. 


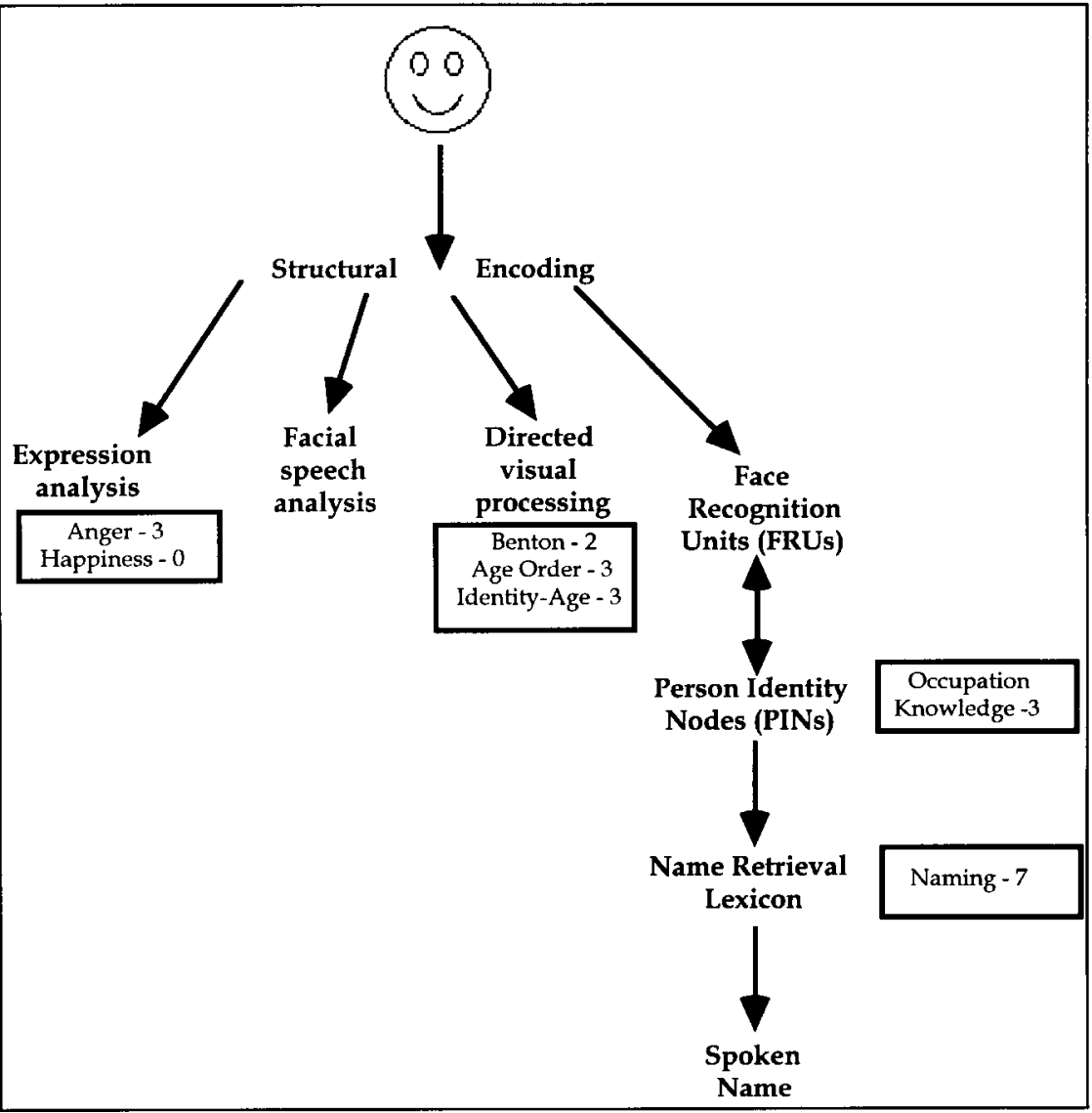

FIG. 1. Bruce and Young (1986) model of face and person recognition, showing the number of patients impaired at each level of processing. A principal feature of the model is that subprocesses of facial expression analysis, unfamiliar face analyses, and familiar face recognition operate independently of each other. The initial stage of analysis is structural encoding, in which an initial primitive facial percept is formed. The viewer-centred description is used both for expression analysis and directed visual-processing routines, such as that used for matching faces for identity. Processing of the expression-independent description follows a parallel route to provide information for familiar face recognition. The Face Recognition Units (FRUs) store representations of familiar faces and interact with Person Identity Nodes (PINs), that hold semantic information about specific individuals - only when this information has been accessed can names be retrieved. This figure shows the number of patients whose performances were impaired (i.e. < 5th percentile) at the different stages and the greater incidence of impairment affecting familiar rather than unfamiliar face processing - in particular, the accessing of semantic information about people from the PINs and name lexicon (i.e. occupation and name retrieval, respectively). 


\section{FAMILIAR BUILDING-NAMING AND IDENTIFICATION}

\section{Method and Procedure}

Naming and identification of familiar buildings (taken from McCarthy, Evans, \& Hodges, 1995) was examined. Subjects were asked to name and identify 25 colour photographs of well-known buildings and monuments (e.g. Eiffel Tower, Statue of Liberty, Nelson's Column, Tower Bridge).

\section{Results}

Patient performance was compared with that of 10 NART IQ and age-matched normal control subjects (see Table 5). As with the famous faces, production of the name was scored as "named". Whereas identification was again divided into "general", and "specific". A response was scored as "identified-general", if the building was not named and minimal identification was given by the country of origin (e.g. Brandenberg Gate $\rightarrow$ "In Germany"). A response was scored as "identified-specific", when additional correct specifying information was given (e.g. Brandenberg Gate $\rightarrow$ " 'In Germany, a monument in Berlin). Two patients (DB and $\mathrm{JH}$ ) had impaired building-naming; the same patients were also impaired at specific and general identification (see Table 5).

\section{Summary}

This task confirms that the familiar face-naming deficit is not due to either a general-naming deficit or a particular difficulty with unique names. One patient (JH) who had impaired building-naming and identification, had intact facenaming and identification and in conjunction with the (more frequent) reverse profile, this double dissociation suggests that the greater incidence of facenaming impairment is not due to a task difficulty effect.

\section{DISCUSSION}

This study documents selective and common neuropsychological deficits affecting verbal recall memory and familiar face-naming in a majority of clinically well-preserved schizophrenic patients. By comparison, a much lower incidence and severity of impairment occurred on tests of: executive, visual perception, language, and unfamiliar face-processing. These findings only partly replicate the case studies of Shallice et al. (1991), who reported more severe and common executive dysfunction in their five chronically hospitalised patients. The present study does, however, extend the conclusions of earlier memory studies (e.g. McKenna et a1., 1990), by documenting memory deficits in patients who: (1) have normal current IQ; (2) less intellectual decline than in previous 
reports; (3) are not chronically hospitalised; (4) not severely symptomatic; and (5) even in patients who have no symptoms whatsoever.

Verbal recall was selectively impaired in so far as visual recall and verbal recognition were intact in all patients. This dissociation distinguishes the memory impairment in schizophrenia from classic amnesia and modalityspecific memory deficits (e.g. Milner, 1958, 1968), where both recall and recognition are typically impaired. Recall tasks are more difficult than recognition tasks and, thus, a task difficulty effect cannot be eliminated; however, several strands of evidence seem to be more consistent with a true difference. This form of "classical" dissociation (i.e. verbal recognition was normal, whereas verbal recall was below the normal range) is considered less susceptible to resource and individual difference artefacts. In other words, the result does not reflect poor performance on both tasks, but with much poorer performance on one task (see Shallice, 1988, p. 228). Importantly, the dissociation concords findings from those group studies where matched difficulty tasks have been used (Calev, 1984a,b; Calev \& Monk, 1982; Calev, Korin, Kugelmass, \& Lerer, 1987; Calev, Venables, \& Monk, 1983). This study also provides both discriminant validity (i.e. the modality-specific effect in our study; with normal visual recall performance in all patients) and convergent validity (i.e. their poor performance on all tasks requiring verbal recall) for the selectivity of the verbal recall deficit. Finally, the patients performed relatively better on other tasks that are often considered more demanding and sensitive to the effects of intellectual decline and generalised impairment (e.g. on tests of executive function: see Shallice, 1988).

Without doubt, some schizophrenic patients perform poorly on both recognition and recall tasks, but this may be more characteristic of severely ill schizophrenic patients (Calev, 1984a, b; Calev \& Monk, 1982; Calev et al., 1983 ) and those with more global cognitive impairment (Clare, McKenna, Mortimer, \& Baddeley, 1993; Tamlyn et a1., 1992). A post-hoc analysis of patients with and without impaired recognition memory in this study provides some support for such an interpretation. Recognition-impaired patients (JH, LR, RA, and TG) had about twice as many impaired performances on all other tasks. Hence, we would suggest that recall dysfunction is the more characteristic or central schizophrenic memory deficit, whereas recognition may be affected only when cognitive function is more widely compromised.

Contrary to many previous group studies, few patients here showed any impairment of unfamiliar face-processing (see Fig. 1) for affect, identity, or episodic recognition memory (see reviews by Cutting, 1985; Morrison et al., 1988; Phillips \& David, 1995). One explanation that needs to be further addressed is that, in previous studies, some patients may have had a general perceptual deficit - the current study appears to be the first to control for this. The failure to find evidence of affect-processing impairment also raises important questions about sole reliance on group studies (see also Archer et al., 
1992). The failure to find impaired affect-processing may also reflect our use of an impairment cut-off rather than statistical comparisons of patients and controls. In this regard, Archer et al. (1992) provided cut-off data (as well as statistical comparisons) for their patients, and their data shows a similar incidence of impairment to that reported here: $3 / 12$ patients had selectively impaired identity-matching and none had selectively impaired affect-processing; similarly they also found the reverse profile of selectively preserved affectprocessing (as reported here in $50 \%$ of patients). Hence, the notion of a selective disturbance of facial emotion identification in schizophrenia receives little support from single case analyses; if anything, preserved affect-processing is more common.

Nevertheless, a majority of patients had severely impaired familiar facenaming. The incidence and severity of this deficit cannot be attributed to normal individual variation or chance, because the majority of patients named fewer faces than all of the 20 NART IQ- and age-matched normal control subjects. The striking and selective correlation between face-naming and unrelated pairedassociates might indicate that both are related to a general declarative memory. However, the selectivity of their memory deficits seems to exclude such an explanation; moreover, a direct comparison of their face-naming for pre- and post-illness famous faces, provided little support for any greater difficulty acquiring, establishing, or consolidating new memory traces since illness onset. Hence, rather than being part of a general mnestic deficit, the face-naming deficit resembles a category-specific anomia for person names (for a review of similar neurological cases, see Hittmair-Delazer et a1., 1994; Semenza, Mondini, \& Zettin, 1995). Barring this, it is difficult to see how a disorder of general cognitive function, a general anomia or mnestic deficit would, for example, impair one patient's (TG) retrieval of the names "Marilyn Monroe", and "Elvis Presley", but leave him able to retrieve the building names "Parthenon', "Acropolis", and "Retort", (the final and most difficult item from the gradednaming test).

Questions remain, however, concerning why these two functions are related and whether the relationship is anatomical or functional? At an anatomical level of explanation, the association between person-naming and paired-associate learning, is unlikely to reflect anatomical proximity; although all neurological cases have left-sided lesions, these range from the frontal-temporal to the occipital and even thalamic regions (see Semenza et al., 1995). On a cognitive level, the "meaninglessness", of the association between names and faces (and between unrelated word pairs) offers a more coherent account and suggests that schizophrenics may have difficulty with imposing a relationship on unrelated items or at least, one that may be strategically useful in aiding retrieval from long-term memory.

Despite the comparative sparing of executive function, the verbal recall and face-naming deficits could yet paradoxically reflect a frontal lobe dysfunction 
(or in the projections to and from this region). As mentioned earlier, the selective impairment of verbal recall distinguishes this memory deficit from classic amnesia and from modality-specific memory deficits. However, a pattern of poor recall but intact recognition memory is sometimes associated with frontal lobe lesions (e.g. Janowsky, Shimamura, Kritchevsky, \& Squire, 1989; Jetter, Poser, Freeman, \& Markowitsch, 1987; Hanley, Davis, Downes, \& Mayes, 1994). For example, Hanley et al. report a closely comparable case of selectively impaired verbal recall with intact recognition and executive test performance in a neurological patient following an anterior communicating artery aneurysm (primarily affecting the head and body of the caudate nucleus in the left hemisphere). They suggested that their patient had difficulty (p. 573) “... setting up effective retrieval strategies that ... access verbal information that is stored in episodic memory"; and that perhaps reflects an impairment of, what Shallice (1988) refers to as, the Supervisory Attentional System (SAS). The SAS is considered to play a critical role in establishing retrieval strategies that enable material to be retrieved from episodic memory and that impairment of the SAS might particularly affect the recall of novel material. In this context, Shallice et al. (1991) speculated that their schizophrenic patients may have just such a deficit. Given that the SAS is necessary for the nonroutine selection of and control of cognitive processes, dysfunction of this system could have especially severe consequences for the retrieval of "meaningless" or arbitrary associations in long-term memory, as well as more generally, for novel material.

In comparison to group studies, this case study analysis has provided a different perspective on the cognitive deficits found in schizophrenic patients. By examining patients who tend to be clinically and intellectually better preserved than those previously documented, we hope to have identified cognitive deficits that might be considered more central to schizophrenia (and not some unique characteristic of a well-preserved subgroup of schizophrenic patients). Moreover, this study has shown that some previously widely accepted cognitive disorders are both more difficult to demonstrate and more questionable when well-preserved individual schizophrenic patients are examined. Despite heterogeneity in the performances of individual patients, a case study approach shows how common and severe deficit profiles can emerge against a background of individual variability on other tests; it permits more meaningful and exacting comparisons with individual neurological cases; and it highlights individual patients, who may require further investigation as either paradigmatic cases or unique exceptions. Thus, it may not be fair to say that schizophrenics “ "... in all probability have nothing in common', (Bentall, 1991, p. 293), but rather that analyses at the level of individual patients may provide the required rationale both for grouping and for separating patients. Unless it is assumed that some disease processes produce an invariant pattern of anatomical/neurochemical dysfunction, the heterogeneity of cognitive performance should generate no greater problems in studying schizophrenic patients than those in studying any 
other pathological group. In pursuing this answer, individual case studies may provide a complementary and constraining influence on group studies; if only to help them avoid continuing to flounder on the rock of heterogeneity.

M anuscript received 13 November 1995

Revised manuscript received 3 July 1996

\section{REFERENCES}

Allen, H.A., Liddle, P.F., \& Frith, C.D. (1993). Negative features, retrieval processes and verbal fluency in schizophrenia. British Journal of Psychiatry, 163, 769-775.

Archer, J., Hay, D.C., \& Young, A.W. (1992). Face processing in psychiatric conditions. British Journal of Clinical Psychology, 31, 45-61.

Archer, J., Hay, D.C., \& Young, A.W. (1994). Movement, face processing and schizophrenia: Evidence of a differential deficit in expression analysis. British Journal of Clinical Psychology, $33,517-528$.

Aylward, E., Walker, E., \& Bettes, B. (1984). Intelligence in schizophrenia: meta-analysis of the research. Schizophrenia Bulletin, $10430-459$.

Bentall, R.P. (1990). Schizophrenia-a suitable case for treatment? In R.P. Bentall (Ed.), Reconstructing schizophrenia (pp.23-60). London: Routledge.

Benton, A.L., Hamsher, K. de S., Varney, N.R., \& Spreen, O. (1978). Facial recognition. New York: Oxford University Press.

Berson, R.J. (1983). Capgras' syndrome. American Journal of Psychiatry, 140, 968-978.

Blanchard, J.J., \& Neale, J.M. (1994). The neuropsychological signature of schizophreniageneralised or differential deficit. American Journal of Psychiatry, 151, 40-48.

Borod, J.C., Martin, C., \& Alpert, M. (1993). Perception of facial emotion in schizophrenic and right brain-damaged patients. Journal of Nervous and Mental Disease, 181, 494-502.

Braff, D.L., Heaton, R., Kuck, J., Cullum, M., Moranville, J., Grant, I., \& Zisook, S. (1991). The generalised pattern of neuropsychological deficits in outpatients with chronic schizophrenia with heterogeneous Wisconsin Card Sorting Test results. Archives of General Psychiatry, 48, 891898 .

Bruce, V., \& Young, A.W. (1986). Understanding face recognition. British Journal of Psychology, $77305-327$.

Calev, A. (1984a). Recall and recognition in mildly disturbed schizophrenics: the use of matched tasks. Psychological Medicine, 14, 425-429.

Calev, A. (1984b). Recall and recognition in chronic nondemented schizophrenics: the use of matched tasks. Journal of Abnormal Psychology, 93, 172-177.

Calev, A., Korin, Y., Kugelmass, S., \& Lerer, B. (1987). Performance of chronic schizophrenics on matched word and design recall tasks. Biological Psychiatry, 22, 699-709.

Calev, A., \& Monk, A.F. (1982). Verbal memory tasks showing no deficit in schizophrenia-fact or artefact? British Journal of Psychiatry, 141, 528-530.

Calev, A., Venables, P.H., \& Monk, A.F. (1983). Evidence for distinct verbal memory pathologies in severely and mildly disturbed schizophrenics. Schizophrenia Bulletin, 9, 247-264.

Chapman, L.J., \& Chapman, J.P. (1973). Problems in the measurement of cognitive deficit. Psychological Bulletin, 79, 380-385.

Clare, L., McKenna, P.J., Mortimer, A.M., \& Baddeley, A.D. (1993). Memory in schizophrenia: what is impaired and what is preserved? Neuropsychologia, 31, 1225-1241.

Cohen, G. (1990). Why is it difficult to put names to faces? British Journal of Psychology, 81, 287297.

Cohen, G., \& Burke, D.M. (1993). Memory for proper names: a review. Memory, 1, $249-263$. 
Crawford, J.R., Besson, J.A.O., Bremner, M., Ebmeier, K.P., Cochrane, R.H.B., \& Kirkwood, K. (1992). Estimation of premorbid intelligence in schizophrenia. British Journal of Psychiatry, $161,69-74$.

Crawford, J.R., Obonswain, M.C., \& Bremner, M. (1993). Frontal lobe impairment in schizophrenia: relationship to intellectual functioning. Psychological Medicine, 23, 787-790.

Crow, T.J. (1980). Molecular pathology of schizophrenia: More than one disease process? British Medical Journal, 280, 66-68.

Cutting, J. (1985). The psychology of schizophrenia. Edinburgh: Churchill Livingstone.

David, A.S. (1994a). Cognitive neuropsychiatry? Psychological Medicine, 23, 1-5.

David, A.S. (1994b). Thought echo reflects the activity of the phonological loop. British Journal of Clinical Psychology, 33, 81-83.

De Renzi, E., \& Faglioni, P. (1976). Normative data and screening power of a shortened version of the Token Test. Cortex, 14, 41-49.

Duffy, L., \& O'Carroll, R. (1995). Memory impairment in schizophrenia-a comparison with that observed in the alcoholic Korsakoff syndrome. Psychological Medicine, 24, 155-166.

Elliott, R., McKenna, P.J., Robbins, T.W., \& Sahakian, B.J. (1995). Neuropsychological evidence for frontostriatal dysfunction in schizophrenia. Psychological Medicine, 25, 619-630.

Feinberg, T.E., Rifkin, A., Schaffer, C., \& Walker, E. (1986). Facial discrimination and emotional recognition in schizophrenia and affective disorders. Archives of General Psychiatry, 43, 276-279.

Folstein, M.F., Folstein, S.E., \& McHugh, P.R. (1975). 'M ini-M ental State': a practical method for grading the cognitive state of patients for the clinician. Journal of Psychiatric Research, 12, 189198.

Frith, C.D. (1992). The cognitive neuropsychology of schizophrenia. Hove, UK: Lawrence Erlbaum Associates Ltd.

Frith, C.D., Leary, J., Cahill, C., \& Johnstone, E.C. (1991). Performance on psychological tests. Demographic and clinical correlates of the results of these tests. British Journal of Psychiatry, 159 (suppl. 13), 26-29.

Gaebel, W., \& Wolwer, W. (1992). Facial expression and emotional face recognition in schizophrenia and depression. European Archives of Psychiatry and Neurological Sciences, $242,46-52$.

Gessler, S., Cutting, J., Frith, C.D., \& Weinman, J. (1989). Schizophrenic inability to judge facial emotion: a controlled study. British Journal of Clinical Psychology, 28, 19-29.

Goldberg, T.E., Greenberg, R.D., Griffin, S.J., Gold, J.M., K leinman, J.E., Pickar, D., Schultz, S.C., \& Weinberger, D.R. (1993a). The effect of clozapine on cognition and psychiatric symptoms in patients with schizophrenia. British Journal of Psychiatry, 162, 43-48.

Goldberg, T.E., Kelsoe, J.R., Weinberger, D.R., Pliskin, N.H., Kirwin, P.D., \& Berman, K.F. (1988). Performance of schizophrenic patients on putative neuropsychological tests of frontal lobe function. International Journal of Neuroscience, 42, 51-58.

Goldberg, T.E., Torrey, E.F., Gold, J.M., Ragland, J.D., Bigelow, L.B., \& Weinberger, D.R. (1993b). Learning and memory in monozygotic twins discordant for schizophrenia. Psychological Medicine, 23, 71-85.

Goldberg, T.E., Weinberger, D.R., Berman, K.F., Pliskin, N.H., \& Podd, M.H. (1987). Further evidence for dementia of prefrontal type in schizophrenia? A controlled study of teaching the Wisconsin Card Sorting Test. Archives of General Psychiatry, 44, 1008-1014.

Goldberg, T.E., Weinberger, D.R., Pliskin, N.H., Berman, K.F., \& Podd, M.H. (1989). Recall memory deficit in schizophrenia: a possible manifestation of prefrontal dysfunction. Schizophrenia Research, 2, 251-257.

Grusser, O.J., \& Landis, T. (1991). Visual agnosias and other disturbances of visual perception and cognition. London: Macmillan Press.

Gruzelier, J., Seymour, K., Wilson, L., Jolley, A., \& Hirsch, S. (1988). Impairments on neuropsychological tests of temperohippocampal and frontohippocampal function in remitting schizophrenia and affective disorders. Archives of General Psychiatry, 45, 623-629. 
Hanley, J.R., Davis, A.D.M., Downes, J.J., \& Mayes, A.R. (1994). Impaired recall of verbal material following rupture and repair of an anterior communicating artery aneurysm. Cognition Neuropsychology, 11, 543-578.

Heimberg, C., Gur, R.E., Erwin, R.J., \& Shtasel, D.L. (1992). Facial emotion discrimination: III. Behavioral findings in schizophrenia. Psychiatry Research, 42, 253-265.

Hittmair-Delazer, M., Denes, G., Semenza, C., \& Mantova, M.C. (1994). Anomia for people's names. Neuropsychologia, 32, 465-476.

Howard, D., \& Patterson, K.E. (1992). The Pyramids and Palm Trees test: a test of semantic access from pictures and words. Bury St. Edmunds, UK: Thames Valley Test Co.

Janowsky, J.S., Shimamura, A.P., Kritchevsky, M., \& Squire, L.R. (1989). Cognitive impairment following frontal lobe damage and its relevance to human amnesia. Behavioural Neuroscience, $103,548-560$.

Jetter, W., Poser, U., Freeman, R.B., \& Markowitsch, J.H. (1986). A verbal long term memory deficit in frontal lobe damaged patients. Cortex, 22, 229-242.

Kerr, S.L., \& Neale, J.M. (1993). Emotion perception in schizophrenia: specific deficit or further evidence of generalized poor performance? Journal of Abnormal Psychology, 102, 312-318.

Kimura, S. (1986). Review of 106 cases with the syndrome of Capgras. Biblioteca Psychiatrica, $164,121-130$.

Kline, J.S., Sm ith, J.E., \& Ellis, H.C. (1992). Paranoid and nonparanoid schizophrenic processing of facially displayed affect. Journal of Psychiatric Research, 26, 169-182.

Kolb, B., \& W ishaw, I.Q. (1983). Performance of schizophrenic patients on tests sensitive to left or right temporal or parietal function in neurological patients. Journal of Nervous and Mental Disease, $171,435-443$.

Laws, K.R. \& McKenna, P.J. (in press). Psychotic symptoms and cognitive deficits: What relationship? Neurocase.

Laws, K.R., McKenna, P.J., \& McCarthy, R.A.M. (1995). Delusions about people. Neurocase, 1, 349-362.

Liddle, P.F. (1987). Schizophrenic syndromes, cognitive performance and neurological dysfunction. Psychological Medicine, 17, 49-57.

Liddle, P.F., \& Crow, T.J. (1984). Age disorientation in chronic schizophrenia is associated with global intellectual impairment. British Journal of Psychiatry, 144, 193-199.

Liddle, P.F., \& Morris, D.L. (1991). Schizophrenic symptoms and frontal lobe performance. British Journal of Psychiatry, 158,340-345.

Lucchelli, F., \& De Renzi, E. (1992). Proper name anomia. Cortex, 28, 221-230.

Marshall, J.C., \& Newcombe,F. (1984). Putative problems and pure progress in neuropsychological single case-studies. Journal of Clinical Neuropsychology, 6, 65-70.

Martin, A. (1988). The search for the neuropsychological profile of a disease state: a mistaken enterprise? Journal of Clinical and Experimental Neuropsychology, 10, 22-23.

Martin, A. (1990). Neuropsychology of Alzheimer's disease: the case for subgroups. In M.F. Schwartz (Ed.), Modular deficits in Alzheimer-type dementia. Cambridge, M A: MIT Press.

McCarthy, R.A.M., Evans, J.J., \& Hodges, J.R. (1995). Topographic amnesia: Spatial memory disorder, perceptual dysfunction, or category specific memory impairment? Journal of Neurology, Neurosurgery, and Psychiatry, 60, 318-325.

McKay, A., McKenna, P.J., \& Laws, K.R. (in press). Severe schizophrenia: What's it like? In P. Halligan \& J. Marshall (Eds.), Method in madness.

McKenna, P., \& Warrington, E.K. (1983). The Graded Naming Test. Windsor, UK: NFERNelson.

McKenna, P.J. (1994). Schizophrenia and related syndromes. Oxford: Oxford University Press.

McKenna, P.J., Tamblyn, D., Lund, C.E., Mortimer, A.M., Hammond, S., \& Baddeley, A.D. (1990). Amnesic syndrome in schizophrenia. Psychological Medicine, 20, 967-972.

McNeil, J.E., \& Warrington, E.K. (1991). Prosopagnosia: A reclassification. Quarterly Journal of Experimental Psychology, 43A, 267-287. 
Meltzer, H.Y. (1992). Dimensions of outcome of clozapine. British Journal of Psychiatry, 160 (suppl. 17), 46-53.

Milner, B. (1958). Psychological deficits produced by temporal-lobe excision. Research Publications-Association for Research in Nervous and Mental Disease, 36, 244-257.

Milner, B. (1968). Visual recognition and recall after temporal-lobe excision in man. Neuropsychologia, 6, 191-209.

Morice, R. (1990). Cognitive inflexibility and pre-frontal dysfunction in schizophrenia and mania. British Journal of Psychiatry, 157, 50-54.

Morrison, R.L., Bellack, A.S., \& Mueser, K.T. (1988). Deficits in facial affect recognition and schizophrenia. Schizophrenia Bulletin, 14, 67-83.

M orrison-Stewart, S.L., Williamson, P.C., Corning, W.C., Kutcher, S.P., Snow, W.G., \& Merskey, H. (1992). Frontal and non-frontal lobe neuropsychological test performance and clinical symptomatology in schizophrenia. Psychological Medicine, 22, 353-359.

Nathaniel-James, D.A., \& Frith, C.D. (1996). Confabulation in schizophrenia: evidence for a new form? Psychological Medicine, 26, 391-399.

Nelson, H.E. (1976). A modified card sorting test sensitive to frontal lobe defects. Cortex, 12, 313324.

Nelson, H.E. (1982). The National Adult Reading Test (NART). W indsor, UK: NFER-Nelson.

Nelson, H.E., \& O'Connell, A. (1978). Dementia: the estimation of premorbid intelligence levels using the new adult reading test. Cortex, 14, 234-244.

Nelson, H.E., Pantelis, C., Carruthers, K., Speller, J., Baxendale, S., \& Barnes, T.R.E. (1990). Cognitive functioning and symptomatology in chronic schizophrenia. Psychological Medicine, $20,357-365$.

Novic, J., Luchins, D.J., \& Perline, R. (1984). Facial affect recognition in schizophrenia: is there a differential deficit? British Journal of Psychiatry, 144, 533-537.

O'Carroll, R., Egan, V., \& MacKenzie, D.M. (1994). Assessing cognitive estimation. British Journal of Clinical Psychology, 33, 193-197.

Owens, D.G.C., \& Johnstone, E.C. (1980). The disabilities of chronic schizophrenia- their nature and the factors contributing to their development. British Journal of Psychiatry, 136, 384-393.

Payne, R.W. (1973). Cognitive abnormalities. In H.J. Eysenck (Ed.), Handbook of abnormal psychology. London: Pitman.

Phillips, M.L., \& David, A.S. (1995). Facial processing in schizophrenia and delusional misidentification: cognitive neuropsychiatric approaches. Schizophrenia Research, 17, $109-114$.

Saykin, A.J., Gur, R.C., Gur, R.E., Mozley, P.D., Resnick, S.M., Kester, D.B., \& Stafiniak, P. (1991). Neuropsychological function in schizophrenia: Selective impairment of memory and learning. Archives of General Psychiatry, 48, 618-624.

Semenza, C., Mondini, S., \& Zettin, M. (1995). The anatomical basis of proper name processing. A critical review. Neurocase, 1, 183-188.

Semenza, C., \& Zettin, M. (1989). Evidence from aphasia for the role of proper names as pure referring expressions. Nature, 342, 678-679.

Shallice, T. (1988). From neuropsychology to mental structure. Cambridge: Cambridge University Press.

Shallice, T., Burgess, P.W., \& Frith, C.D. (1991). Can the neuropsychological case-study approach be applied to schizophrenia? Psychological Medicine, 21, 661-673.

Shallice, T., \& Evans, M.E. (1978). The involvement of the frontal lobes in cognitive estimation. Cortex, 14, 294-303.

Spitzer, R.L., Endicott, J., \& Robbins, E. (1978). Research diagnostic criteria for a selected group of functional disorders. New York: Biometric Research, New York State Psychiatric Institute.

Stevens, M., Crow, T.J., Bowman, M.J., \& Coles, E.C. (1978). Age disorientation in schizophrenia: a constant prevalence of 25 per cent in a chronic mental hospital population? British Journal of Psychiatry, 133, 130-136. 
Strauss, M.E., \& Summerfelt, A. (1994). Response to Serper and Harvey. Schizophrenia Bulletin, $20,13-21$.

Tamlyn, D., McKenna, P.J., Mortimer, A.M., Lund, C.E., Hammond, S., \& Baddeley, A.D. (1992). Memory impairment in schizophrenia: its extent, affiliations and neuropsychological character. Psychological Medicine, 22, 101-115.

Taylor, M.A., \& Abrams, R. (1984). Cognitive impairment in schizophrenia. American Journal of Psychiatry, 141, 196-201.

Walker, E., McGuire, \& Bettes, B. (1984). Recognition and identification of facial stimuli by schizophrenics and patients with affective disorders. British Journal of Clinical Psychology, 23, $37-44$.

Warrington, E.K. (1984). Recognition Memory Test. Windsor, UK: NFER-Nelson.

Warrington, E.K., \& James, M. (1991). The visual object and space perception battery. Bury St. Edmunds, UK: Thames Valley Test Co.

Warrington, E.K., \& Taylor, A.M. (1973). The contribution of the right parietal lobe to object recognition. Cortex, 9, 152-164.

Wechsler, F. (1955). The Wechsler Adult Intelligence Scale. New York: The Psychological Corporation.

Wechsler, F. (1987). The Wechsler Memory Scale (Revised). New York: The Psychological Corporation. 
Copyright of Cognitive Neuropsychiatry is the property of Psychology Press (T\&F) and its content may not be copied or emailed to multiple sites or posted to a listserv without the copyright holder's express written permission. However, users may print, download, or email articles for individual use. 